\title{
Expressão de TGFß1 mRNA nas fases iniciais de expansão da sutura palatina mediana
}

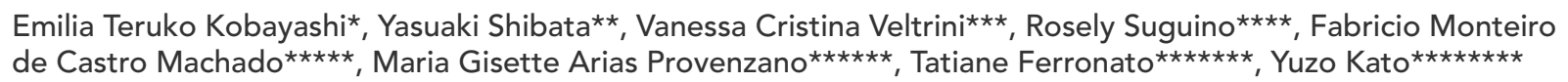

\section{Resumo}

Introdução: a expansão da maxila induz a formação de novo osso na sutura palatina mediana por um processo de proliferação e diferenciação celular. A força de expansão pode estimular, nas células progenitoras, a produção de citocinas com atividade osteoindutiva, tais como o transforming growth factor $\beta 1$ (TGF $\beta 1$ ). Objetivos: o principal objetivo deste estudo foi determinar a função dessa citocina nos estágios iniciais de expansão da sutura palatina mediana. Métodos: um aparelho ortodôntico foi instalado entre os molares superiores direito e esquerdo de ratos com 4 semanas de idade. A força de expansão inicial foi de $50 \mathrm{~g}$. Os grupos controle e experimental foram sacrificados nos dias 0, 2 e 5. Cortes bucais de 6um foram obtidos e sujeitos à técnica de hibridização in-situ. Resultados: dois dias após a aplicação de força, as células osteocondroprogenitoras, distribuídas no lado interno do tecido cartilaginoso, exibiram altos níveis de transcrição de transforming growth factor $\beta 1$. No dia 5, o nível de transcrição de TGF $\beta 1$ foi observado nos osteócitos e nas células osteoblásticas, na superfície do novo osso. A atividade osteoblástica foi confirmada por meio de um estudo imunohistoquímico utilizando-se Osteocalcina-Pro (OC-Pro). Conclusões: os dados sugerem que a expansão da sutura palatina induz a diferenciação de células osteocondroprogenitoras em osteoblastos, estimuladas pela produção de citocinas.

Palavras-chave: Transforming growth factor $\beta 1$. Proliferação. Diferenciação. Osteoblastos. Hibridização "in-situ".

\section{INTRODUÇÃO}

A cartilagem da sutura palatina mediana de ratos em crescimento é composta por camadas de células precartilaginosas, localizadas na parte central da sutura, e cartilaginosas maduras, em ambos os lados da camada precartilaginosa. A primeira camada é preenchida por células pré-condroblásticas e mesenquimais não diferenciadas, que apresentam alta capacidade de proliferar e diferenciarse em condrócitos e osteoblastos.

* Doutora em Ortodontia e Ortopedia Facial pela Nagasaki University School of Dentistry, Japão. Professora adjunta, Disciplina de Odontologia Pediátrica I e II, no Centro Universitário de Maringá (CESUMAR).

** Doutor em Patologia pela Nagasaki University School of Dentistry, Japão. Professor Adjunto, Division of Oral Pathology and Bone Metabolism, Nagasaki University Graduate School of Biomedical Science, Japão.

*** Doutora em Patologia pela FOB-USP. Professora de Patologia do Departamento de Odontologia da UEM.

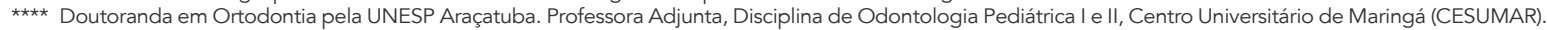

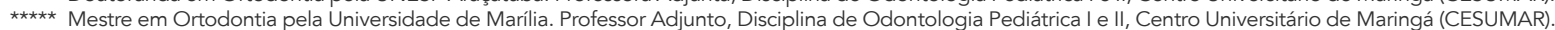

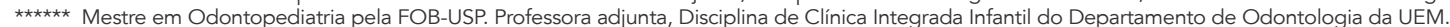

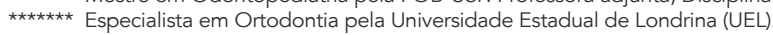

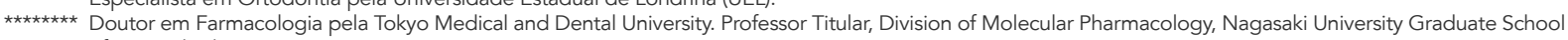
of Biomedical Science, Japão. 
A formação óssea na sutura palatina mediana inicia-se na região externa do tecido cartilaginoso por ossificação endocondral. À medida que a força ortodôntica expansional é aplicada à sutura, um novo processo de formação óssea é iniciado, a ossificação intramembranosa, na parte interna do tecido cartilaginoso ${ }^{7,18}$. Esse processo envolve a proliferação das células mesenquimais não diferenciadas e a diferenciação dessas células em osteoblastos. Kobayashi et al. ${ }^{7}$ relataram a resposta celular precoce causada pela indução da força ortodôntica, sendo observado um aumento na expressão de Proliferating Cell $\mathrm{Nu}$ clear Antigen (PCNA), um marcador específico para proliferação celular, e várias outras proteínas da matriz óssea, na região interna do tecido cartilaginoso. Os resultados demonstraram que o estresse mecânico é um fator importante na mediação de proliferação e diferenciação celular, transformando células osteocondroprogenitoras em osteoblastos.

Entretanto, o mecanismo molecular da resposta celular para a atividade proliferativa e diferenciação de células progenitoras em osteoblastos, mediadas pela aplicação de força expansional, não está totalmente esclarecido.

Muitos autores têm demonstrado o envolvimento do Transforming Growth Factor (TGF $\beta 1$ ) - uma citocina pertencente ao grupo de "TGF $\beta$ superfamily" - na formação óssea tanto em experimentos in vivo ${ }^{11,12,14}$ como in vitro ${ }^{4,8,9}$.

Em decorrência da alta capacidade osteogênica dessa citocina, foi proposta a execução do presente trabalho, cujo objetivo foi mensurar os níveis de transcrição de TGFß1, por meio da técnica de hibridização in situ, quando uma força ortodôntica expansora era aplicada à sutura palatina mediana de ratos em crescimento.

\section{MATERIAL E MÉTODOS}

Expansão da sutura palatina mediana

Ratos Wistar, com 4 semanas de vida (Charles River Corporation, Kanagawa, Japão), pesando aproximadamente $75,2 \pm 8 \mathrm{~g}$, foram mantidos em biotério com disponibilidade de água e ração à vontade (Oriental Yeast, Tóquio, Japão).

Eles foram tratados de acordo com o protocolo aprovado pela Comissão de Ética para animais da Universidade de Nagasaki, Japão. Um aparelho ortodôntico $(0,014$ " Co-Cr wire, green Elgiloy Semi-resilient wire, Rocky Mountain Morita Corporation, Denver, CO, EUA), com intuito de expandir o palato, foi instalado nos molares superiores direito e esquerdo, como descrito por Kobayashi et al. ${ }^{7}$

Inicialmente, a força expansional foi ajustada para 50g com um tensiômetro (Tomy International Co., Tóquio, Japão). Os grupos controle e experimental foram sacrificados nos dias 0,2 e 5 . Cada grupo foi composto por três animais.

\section{Preparação do tecido para a imunohistoquímica}

A maxila foi removida cirurgicamente e fixada por imersão em paraformaldeído a $4 \%$, overnight a $4^{\circ} \mathrm{C}$. Após a fixação, a maxila foi descalcificada em ácido etilenodiamino tetra-acético (EDTA) a $10 \%$ por 10 dias e à temperatura de $4^{\circ} \mathrm{C}$. A maxila foi desidratada em uma série graduada de etanol e embebida em parafina. Cortes seriados de $6 \mu \mathrm{m}$ de espessura foram obtidos na região mesial da raiz do primeiro molar superior e montados em lâminas revestidas com 3-aminopropyl-triethoxysilane.

\section{Preparação do tecido para hibridização in situ}

O preparo dos cortes para hibridização in situ foi similar àqueles para a imunohistoquímica. Todas as soluções estavam com atividade livre de RNAse, por meio da adição de DEPC (diethyl pyrocarbonate) a $0,1 \%$ em $\mathrm{H}_{2} \mathrm{O}$.

Preparação de probes cRNA marcados com digoxigenina para hibridização in situ

Os plasmídeos contendo TGFß1 cDNA foram 
transferidos para a bactéria Escherichia coli com intuito de amplificar a soma de cDNA.

O TGFß1 cDNA foi cortado na região BamHI/ HindIII e subclonado no vetor Bluescript KS+ e usado como modelo para a produção de cRNA.

RNA antisense de fita simples marcado com digoxigenina (complementar) e sense (não complementar) foi preparado com kit de marcadores DIG-RNA (Boehringer Mannheim, Alemanha).

A transcrição foi executada usando-se T3 ou T7 RNA polimerase.

As marcações com digoxigenina foram confirmadas pelo uso de hibridização em filtro. Cada probe reage somente com uma fita reversa correspondente de RNA.

\section{Hibridização in situ}

A hibridização in situ foi executada pelo método de Nakase et al. ${ }^{13}$

Após o bloqueio da atividade da fosfatase alcalina com ácido, os cortes foram incubados com RNA probesemarcadoscomDIG-UTP $(1,5 \mathrm{~g} / \mathrm{ml})$, overnight a $55^{\circ} \mathrm{C}$. Após lavagem extensiva e tratamento com RNAse, os probes marcados com DIG foram detectados com anticorpo antiDIG conjugado com fosfatase alcalina e 5 bromo 4-cloro-3 indolil fosfatase como substrato, usando-se um kit de detecção de ácido nucléico (Boehringer Mannheim).

O controle incluía: (a) a hibridização com sense (mRNA) probe e (b) hibridização com não probe.

\section{Imunohistoquímica e histoquímica}

A imunohistoquímica foi executada pelo método de peroxidase-anti-peroxidase descrito por Sakai et al. ${ }^{16}$ Resumidamente, os cortes foram pré-tratados antes da incubação com os primeiros anticorpos. $\mathrm{O}$ antissoro policlonal de coelho contra Cathepsin $\mathrm{K}(\mathrm{CK})^{3}$ e Osteocalcina-Pro (OC-Pro) ${ }^{2}$ de ratos foram diluídos na concentração de 1:200 e 1:100, respectivamente, em tampão de bloqueio, e aplicados nos cortes overnight a $4^{\circ} \mathrm{C}$.
No dia seguinte, os cortes foram lavados e então incubados com o segundo anticorpo (anticorpo de cabra anti-IgG de coelho).

O local da imunorreatividade foi visualizado com peroxidase-anti-peroxidase e diamino benzidina, com precipitações na cor marrom de benzidina $^{17}$.

A imunoreatividade para PCNA foi executada usando-se anticorpo monoclonal de camundongo (clone PC10, DAKO, Tóquio, Japão) como primeiro anticorpo, na diluição de 1:50, à temperatura de $4^{\circ} \mathrm{C}$, overnight.

Os cortes foram corados com streptoavidinabiotina-peroxidase (Histofine ABC kit-Nichirei Co. Ltd., Tóquio), seguindo as instruções do fabricante.

A imunoreatividade negativa foi observada nos cortes controle usando-se tanto soro normal de coelho (diluição de 1:100) como IgG normal de camundongo $(100 \mathrm{~g} / \mathrm{ml})$. A histoquímica para hematoxilina e eosina foi executada de acordo com o método descrito por Lyon ${ }^{10}$.

\section{RESULTADOS}

Mudanças histológicas observadas durante a expansão da sutura palatina mediana

No dia 0 , a sutura palatina mediana apresentava-se preenchida por um tecido de aspecto cartilaginoso, composto centralmente por células compatíveis a pré-condroblastos, bem como por células mesenquimais indiferenciadas, provavelmente dotadas de capacidade osteocondroprogenitora. Perifericamente, as células presentes exibiam caracteres de condroblastos maduros e/ou condrócitos (Fig. 1A).

No dia 2, observou-se um deslocamento das células cartilaginosas maduras em lateralidade, enquanto as imaturas mantiveram-se na região central. Além disso, observou-se uma aglomeração de células na região de limite entre pré-condroblastos e condroblastos maduros (Fig. 1B).

Após cinco dias de expansão, já era possível visualizar, permeando o tecido cartilaginoso, trabéculas de osso imaturo neoformado (Fig. 1C). 


\section{Hibridização in situ e avaliação imunohistoquímica}

A localização de TGFß1 mRNA na cartilagem da sutura palatina mediana foi estudada por hibridização in situ, utilizando-se marcadores DIG para cRNA probes.

No dia 0 , uma reação positiva para TGFß1 mRNA (Fig. 2A) foi observada nos osteoblastos maduros, situados na periferia das trabéculas, lateralmente às camadas de células compatíveis com condroblastos (ver setas na Fig. 2A).

A imunoreatividade para PCNA (Fig. 2B) foi positiva nos pré-condroblastos da região central, bem como em alguns condroblastos maduros e hipertróficos localizados na periferia da sutura. Células clásticas apareceram impregnadas por substância cromógena quando se utilizou a marcação para Cathepsin (CK) (Fig. 2C), principalmente na periferia externa do tecido cartilaginoso, na transição para o tecido ósseo.

Após dois dias de tratamento, a imunopositividade para TGFB1 mRNA (Fig. 3A) tornou-se mais intensa na região de limite entre pré-condroblastos e condroblastos maduros.
Uma forte marcação para PCNA (Fig. 3B) foi observada na mesma área. Em concordância com o padrão de reatividade observado no grupo controle, obteve-se marcação indicativa de atividade clástica, ou seja, positiva para $\mathrm{CK}$, na face externa do tecido cartilaginoso.

Nos dias seguintes, a expressão de TGFß1 mRNA (Fig. 4A) intensificou-se nos osteócitos (setas vazias) e osteoblastos (setas cheias) situados dentro e na superfície do osso neoformado, respectivamente (dia 5).

A atividade secretora de osteoblastos observada na periferia das trabéculas foi confirmada por meio de estudo imunohistoquímico para Osteocalcina-Pro (OC-Pro) (Fig. 4B). A atividade clástica (Fig. 4C) exibiu os mesmos padrões de marcação observados no dia 0 (controle).

\section{DISCUSSÃO}

No dia 0 , a imunoreatividade para PCNA foi positiva nas células pré-condroblásticas localizadas na área central da sutura palatina mediana e em alguns condroblastos maduros e hipertróficos, indicando que essas células estão em estágios de
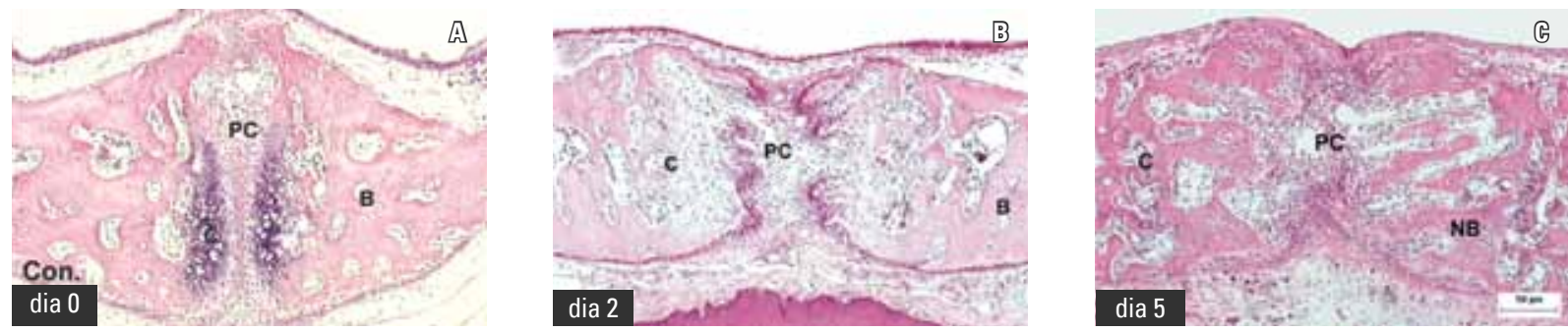

FIGURA 1 - Sequência histológica de mudanças na sutura palatina mediana após a aplicação de força expansional (Con= controle; PC= células precartilaginosas; $c=$ células cartilaginosas; $B=0$ osso; $N B=$ novo osso; $50 \mu \mathrm{m}$ para os painéis $A, B$ e $C$ ).
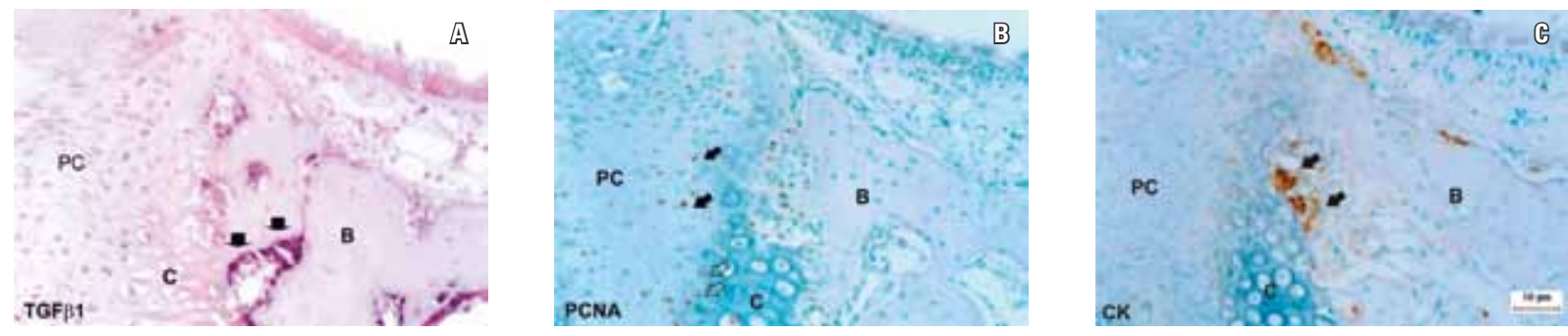

FIGURA 2 - Expressão de TGFß1 mRNA (A), PCNA (B) e CK (C), no dia 0 (TGF $\beta 1=$ Transforming Growth Factor $\beta 1$; PCNA= Proliferating Cell Nuclear Antigen; CK= Cathepsin $\mathrm{K} ; 10 \mu \mathrm{m}$ para os painéis $\mathrm{A}, \mathrm{B}$ e C). 

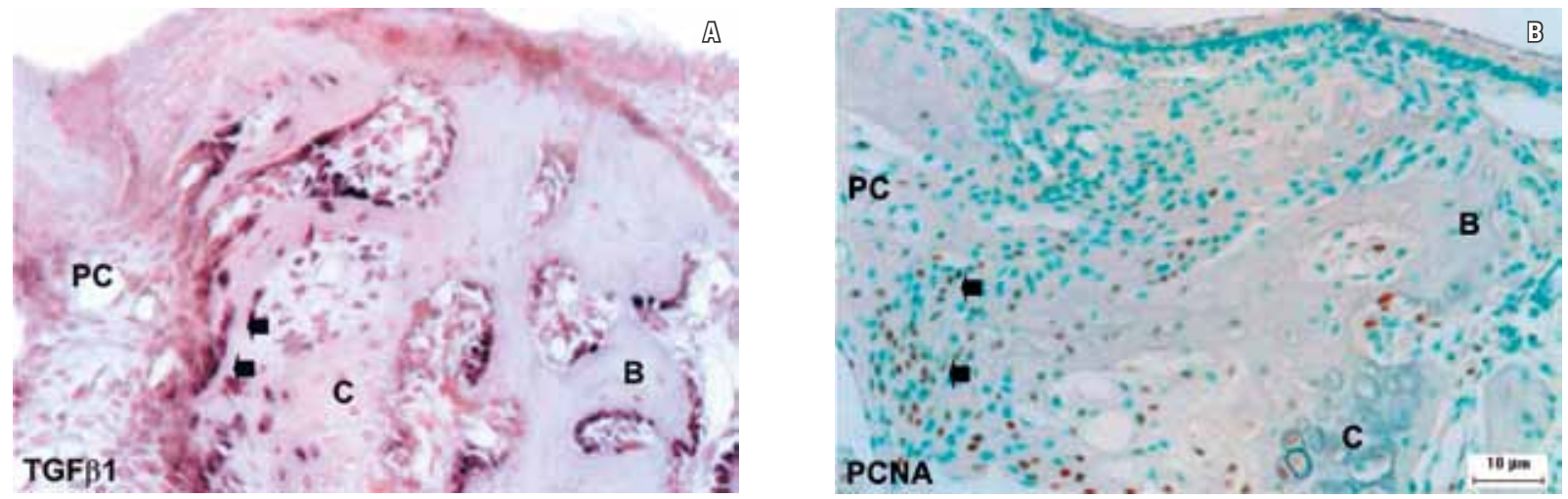

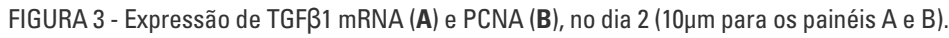
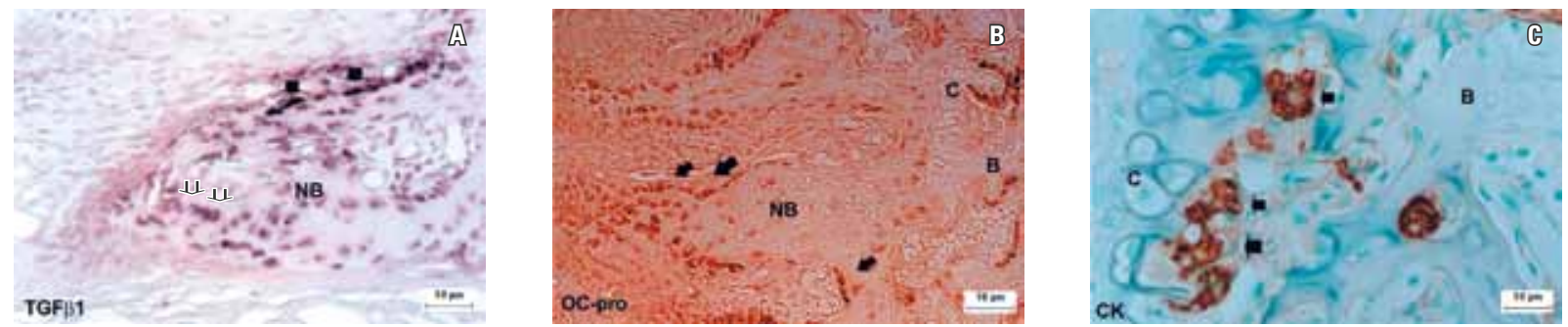

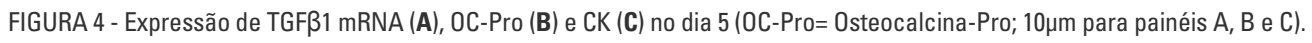

divisão celular. PCNA é uma proteína expressa no núcleo das células e age como cofator da DNA polimerase delta durante a fase de síntese do DNA ${ }^{1}$. Por essa razão, a sua expressividade foi utilizada como meio para medir os níveis de proliferação celular. Durante essa fase, a atividade proliferativa pode estar relacionada ao desenvolvimento transversal normal do palato ${ }^{7}$.

A modificação na localização dos fenômenos proliferativos ocorreu no segundo dia após a aplicação da força expansional, indicada pelo alto nível de expressão de PCNA, exatamente no limite entre as células pré-condroblásticas e condroblastos maduros.

Previamente em outro estudo ${ }^{7}$, foram observados uma positiva imunorreatividade para osteocalcina (OCN), um marcador específico para osteoblasto, e atividade da fosfatase alcalina (Alpase) no mesmo período e localização, sugerindo que as células osteocondroprogenitoras diferenciam-se em osteoblastos em resposta à força expansional.

Corroborando com esses resultados, observaram-se, na presente pesquisa, altos níveis de transcrição de TGFß1 mRNA nessa mesma região no dia 2, assim como em osteoblastos maduros no dia 0 .

A expressão de TGFß1 associada à formação de novo osso tem sido investigada por muito autores. Noda e Camilliere ${ }^{14}$ reportaram a ocorrência de formação óssea depois que TGFß1 foi diretamente injetada no osso da calvária de ratos recém-nascidos.

Além disso, a regulação de TGFß1 na diferenciação de osteoblasto a partir de células mesenquimáticas não diferenciadas foi também mencionada por Joyce et al. ${ }^{5}$ Os autores relataram que TGFß1 induz a diferenciação de células mesenquimáticas do periósteo em osteoblastos, estimulando-as para a proliferação e síntese de matriz proteica extracelular. 
TGFß1 pode, ainda, mediar a osteogênese por meio do efeito quimiotáxico sobre as células osteoblásticas precursoras, recrutando-as para a região de formação óssea ${ }^{15}$.

Nos estágios finais do tratamento (dia 5), o processo de formação de novo osso continua desenvolvendo estruturas ósseas em forma de colunas que crescem no centro da sutura.

A imunorreatividade para OC-Pro, um marcador específico de osteoblasto, na superfície do novo osso formado confirma a presença da atividade osteoblástica nessa região.

A transcrição de TGFß1 foi observada em osteócitos e células osteoblásticas no novo osso formado, sugerindo que essas citocinas estão envolvidas na regulação da diferenciação de células mesenquimáticas não diferenciadas em osteoblastos.

Durante todo o período experimental (dias 0, 2 e 5), as células clásticas expressaram imunorreatividade para $\mathrm{CK}$, exclusivamente na região lateral externa ao tecido com aspecto cartilaginoso, seguindo o processo normal de reabsorção da matriz cartilaginosa calcificada. Essa protease, produzida pelo clasto, exerce a função principal de auxiliar na degradação de proteínas da matriz óssea, como o colágeno tipo I e II e a osteonectina pelo clasto ${ }^{3}$.

Entretanto, nenhuma atividade clástica foi observada na região interna ao tecido cartilaginoso, mesmo observando-se a presença de vasos sanguíneos que propiciariam a migração de células clásticas precursoras nesse local. Essas alterações na atividade clástica ocorreram, provavelmente, pelos altos níveis de expressão de TGFß1, que apresentam a capacidade de inibir a diferenciação de células clásticas precursoras, e também a capacidade de reabsorção dos clastos maduros ${ }^{6}$.

\section{CONCLUSÕES}

Considerando os resultados obtidos no presente trabalho, pode-se concluir que:

A expansão da cartilagem da sutura palatina mediana aumentou a expressão de TGFß1 nas células localizadas no limite entre a camada de células precartilaginosas e cartilaginosas, em osteócitos, e osteoblastos na superfície do novo osso formado.

A expressividade de TGF $\beta 1$, associada à presença, no dia dois, de Osteocalcina (OCN) e Fosfatase Alcalina no limite entre a camada de células precartilaginosas e cartilaginosas, pode ser indicativa do início do processo de diferenciação de células osteocondroprogenitoras em osteoblastos.

A neoformação óssea na região interna ao tecido cartilaginoso é essencialmente por ossificação intramembranosa.

A ausência de atividade clástica na região interna do tecido cartilaginoso expandido pode estar relacionada à alta expressividade de TGFß1.

\section{AGRADECIMENTOS}

Esse estudo foi financiado pela JICA (Japan International Cooperation Agency). Meu sinceros agradecimentos ao Dr. Hideaki Sakai (in memoriam), por sua brilhante orientação; ao José Antônio, técnico laboratorial da Universidade Estadual de Maringá (UEM), por contribuir com os seus valiosos conhecimentos técnicos.

Enviado em: setembro de 2008 Revisado e aceito: abril de 2009 


\title{
The expression of TGF 1 mRNA in the early stage of the midpalatal suture cartilage expansion
}

\begin{abstract}
Introduction: The application of an orthodontic expansion force induces bone formation at the midpalatal suture because of cell proliferation and differentiation. Expansion forces may stimulate the production of osteoinductive cytokines, such as transforming growth factor $\beta 1$ (TGF $\beta 1$ ), in the progenitor cells. Objectives: This study determined the role of TGF $\beta 1$ in the early stage of midpalatal suture cartilage expansion. Methods: A rectangular orthodontic appliance was placed between the right and left upper molars of 4-week-old rats. The initial expansion force was $50 \mathrm{~g}$. Animals in the control and experimental groups were sacrified on days 0, 2, and 5 and $6 \mu \mathrm{mm}$ thick sections were prepared for an in situ hybridization technique. Results: Two days after the application of force, prechondroblastic and undifferentiated mesenchymal cells distributed along the inner side of the cartilaginous tissue had high levels of TGF $\beta 1$ transcription. On day 5, the TGF $\beta 1$ transcription was found in osteocytes and osteoblastic cells on the surface of newly formed bone. Immunohistochemistry using Osteocalcin-Pro (OC-Pro) confirmed osteoblastic activity. Conclusions: Results suggest that the expansion of midpalatal suture cartilage induces differentiation of osteochondroprogenitor cells into osteoblasts after stimulation by cytokine production.
\end{abstract}

Keywords: Transforming growth factor $\beta 1$. Proliferation. Differentiation. Osteoblast. In-situ hybridization.

\section{REFERÊNCIAS}

1. Bravo R, Frank R, Blundell PA, MacDonald-Bravo H. Cyclin/PCNA is the auxiliary protein of DNA polymerase-delta. Nature. 1987 Apr 2-8;326(6112):515-7.

2. Hashimoto F, Kobayashi Y, Kamiya T, Kobayashi K, Kato Y, Sakai H. Antigenicity of pro-osteocalcin in hard tissue: the authenticity to visualize osteocalcin-producing cells. J Bone Miner Metab. 1997 Sep;15(3):122-31.

3. Hou WS, Li Z, Gordon RE, Chan K, Klein MJ, Levy R, et al. Cathepsin $\mathrm{k}$ is a critical protease in synovial fibroblast-mediated collagen degradation. Am J Pathol. 2001 Dec;159(6):2167-77.

4. Janssens K, Ten Dijke P, Janssens S, Van HW. Transforming growth factor beta 1 to the bone. Endocr Rev. 2005 Oct;26(6):743-4.

5. Joyce ME, Roberts AB, Spom MB, Bolander ME. Transforming growth factor-beta and the initiation of chondrogenesis and osteogenesis in the rat femur. J Cell Biol. 1990 Jun;110(6):2195-207.

6. Karst M, Gorny G, Galvin RJ, Oursler MJ. Roles of stromal cell RANKL, OPG, and M-CSF expression in biphasic TGF-beta regulation of osteoclast differentiation. J Cell Physiol. 2004 Jul;200(1):99-106.

7. Kobayashi ET, Hashimoto F, Kobayashi Y, Sakai E, Miyazaki Y, Kamiya $T$, et al. Force-induced rapid changes in cell fate at midpalatal suture cartilage of growing rats. J Dent Res. 1999 Sep;78(9):1495-504

8. Lee JY, Kim KH, Shin SY, Rhyu IC, Lee YM, Park YJ, et al. Enhanced bone formation by TGF1 releasing collagen/ chitosan microgranules. J Biomed Mater Res A. 2006 Mar 1;76(3):530-9.

9. Lieb E, Vogel T, Milz S, Dauner M, Schulz MB. Effects of Transforming Growth Factor 1 on bone-like tissue formation in three-dimensional cell culture II: osteoblastic differentiation. Tissue Eng. 2004 Sep-Oct; 10(9-10):1414-25.

10. Lyon $\mathrm{H}$. Hematoxylin-eosin: an example of a common histological staining method. In: Celis JE. Cell biology: a laboratory handbook. 2nd ed. San Diego: Academic Press; 1998. p. 232-7.
11. Mackie EJ, Trechsel U. Stimulation of bone formation in vivo by transforming growth factor: remodeling of woven bone and lack of inhibition by indomethacin. Bone. 1990;11(4):295-300.

12. Marcelli C, Yates AJ, Mundy GR. In vivo effects of human recombinant transforming growth factor on bone turnover in normal mice. J Bone Miner Res. 1990 Oct;5(10):1087-96.

13. Nakase T, Takaoka K, Hirakawa K, Hirota S, Takemura T, Onoue $\mathrm{H}$, et al. Alterations in the expression of osteonectin, osteopontin and osteocalcin mRNAs during the development of skeletal tissues in vivo. Bone Miner. 1994 Aug;26(2):109-22.

14. Noda M, Camilliere JJ. In vivo stimulation of bone formation by transforming growth factor-beta. Endocrinology. 1989 Jun;124(6):2991-4.

15. Pfeilschifter J, Wolf O, Naumann A, Minne HW, Mundy GR, Zielgler R. Chemotactic response of osteoblastic-like cells to transforming growth factor beta. J Bone Miner Res. 1990 Aug. 5(8):825-30

16. Sakai H, Saku T, Kato Y, Yamamoto K. Quantitation and immunohistochemical localization of cathepsins $E$ and D in rat tissues and blood cells. Biochim Biophys Acta. 1989 May 31;991(2):367-75.

17. Sternberger LA, Hardy PH Jr, Cuculis JJ, Meyer HG. The unlabeled antibody enzyme method of immunohistochemistry. Preparation and properties of soluble antigen-antibody complex (horseradish peroxidase) and its use in identification of spirochetes. J Histochem Cytochem. 1970 May;18(5):315-33.

18. Takahashi I, Mizoguchi I, Nakamura M, Sasano Y, Saitoh $\mathrm{S}$, Kagayama M, et al. Effects of expansive force on the differentiation of midpalatal suture cartilage in rats. Bone. 1996 Apr;18(4):341-8

Endereço para correspondência

Emilia Teruko Kobayashi

Rua Professor Samuel Moura 1039, Jd. Araxa

CEP: 86.061-060 - Londrina / PR

E-mail: etk2207@terra.com.br 